\title{
DIMENSIÓN JURÍDICA DE LA EDUCACIÓN INCLUSIVA: ACCESO, PERMANENCIA Y PROMOCIÓN
}

\author{
LEGAL DIMENSION OF INCLUSIVE EDUCATION: ACCESS, PERMANENCE AND \\ PROMOTION
}

María Méndez Rocasolano

Full Bright de Harvard. Responsable del Departamento de Derecho Constitucional y Ambiental - UCAM. E-mail: mmrocasolano@ucam.edu

Ángel Sornichero Martínez

Maestro funcionario. Doctorando en la Universidad Católica San Antonio - UCAM. E-mail: angel.sornichero@murciaeduca.es

Convidadas

RESUMEN: La educación inclusiva es un término poliédrico que surge de la evolución de las prácticas de integración que vienen dándose desde finales del siglo pasado y que la última reforma de la Ley de Educación ha incorporado al debate educativo, social y político actual. La reflexión sobre su naturaleza jurídica como principio y como derecho con sus correspondientes consecuencias en la política educativa, en la práctica de la igualdad, en el desarrollo de la dignidad de la persona y de la personalidad y en el modelo del Estado Social de Derecho del siglo XXI dirigen la mirada hacia un nuevo derecho. El punto de partida es un concepto amplio de educación inclusiva con tres dimensiones indisolublemente trabadas entre sí, es decir de acceso, de permanencia y de promoción dentro del sistema educativo y desde este planteamiento se revisa el tratamiento jurídico de la materia en el ámbito internacional y nacional como un todo que determina el contenido esencial de un posible derecho fundamental a la igualdad en la educación que ha de reconocerse normativa e institucionalmente siendo coherente con el discurso de los derechos humanos. Partiendo de los fundamentos axiológicos de la normativa reguladora de la materia, del derecho comparado y de la jurisprudencia, mediante teorías innovadoras como la dinamogénesis de los valores, concretamos con metodología racional deductiva el contenido de este derecho que la sociedad demanda. Se expresa en la Convención Internacional de los Derechos de las Personas con Discapacidad situándose como finalidad concreta dentro de la Agenda 20-30 que el Mundo se ha dado para lograr un mundo mejor, en concreto como expresión de los objetivos y metas de desarrollo sostenible 4 la educación de calidad y 10 la reducción de desigualdades.

Palabras clave: Educación inclusiva. Discriminación. Discapacidad. Igualdad educacional. Dinamogénesis de los valores.

ABSTRACT: Inclusive education is a polyhedral term that arises from the evolution of integration practices that have been taking place since the end of the last century, it is into the current educational, social and political debate trought the latest reform of the Education Spanish Law. 
The reflection on its legal nature as a principle and as a right with its corresponding consequences in educational policy, in the practice of equality, in the development of the personal dignity and in the model of the Social State of Law of the 21st century, at lof them look towards a new right. The starting point is a broad concept of inclusive education with three dimensions hardly linked, access, permanence and promotion within the educational system. The review of the legal treatment of the matter in the international and national arena determines the essential content of a possible fundamental right to equality in education. The right must be recognized normatively and institutionally, being coherent with the discourse of human rights. Starting from the axiological foundations of the regulatory norms of the matter, comparative law and jurisprudence, through innovative theories such as the dynamogenesis of values, we can crreate with rational and deductive methodology the esence of this right that society demands. It is expressed in the International Convention on the Rights of Persons with Disabilities, placing itself as a specific purpose within the 20-30 Agenda that the World has given itself to achieve a better world, specifically as an expression of the objectives and goals of sustainable development 4 quality education and 10 the reduction of inequalities

Keywords: Inclusive education. Discrimination. Disability. Equal education. Dynamogenesis of values.

SUMÁRIO: Introducción. Escolarización, permanencia y promoción, friso juridico conceptual de la educacion inclusiva. La naturaleza jurídica de la inclusión educativa, principio y derecho. Fundamentación axiológica del derecho a la educación inclusiva. Referencias bibliográficas.

\section{INTRODUCCIÓN}

La educación inclusiva supone una forma nueva de entender la escuela, sobre todo para el alumnado que presenta discapacidades graves y permanentes que viene tomando fuerza desde finales del siglo pasado dentro de las propuestas vinculadas a los derechos de las personas con discapacidad. En la actualidad, la integración en los centros educativos de los alumnos con capacidades diferentes cobra protagonismo dentro de las políticas educativas y sociales, afectando no sólo al momento de la escolarización, sino también al tratamiento que tiene este colectivo durante su formación donde la falta de oportunidades en las enseñanzas postobligatorias y laborales en muchos casos condenan a estos alumnos al ostracismo.

El carácter poliédrico y multidisciplinar de la educación inclusiva no ayuda a concretar su contenido, lo que desde el punto de vista legal es imprescindible para garantizar la seguridad jurídica. De hecho, como indica Echeita y Ainscow (2011) esta idea se manifiesta en el ámbito internacional a través de múltiples aportaciones conceptuales (Ainscow, Farrell \& Tweddle, 2000, Dyson, 2001, Echeita 2006, 2008, Escudero y Martínez, 2011, Muñoz Villalobos, 2019). Frente a sus detractores, donde destacan Connolley y Sarromaa (2009), especialmente coinciden los especialistas en el error que supone la asimilación de los términos integración e inclusión pues si bien se refieren a realidades similares presentan importantes diferencias de las que derivan consecuencias jurídicas educativas muy dispares. Una de sus manifestaciones se observa en la propia finalidad de la educación inclusiva dirigida no sólo a personas con discapacidad, sino a alumnos en riesgo de exclusión social por razón de diversidad racial, clase social, religión, género u otras diferencias (Blanco, 2006).

Desde esta perspectiva hablamos de inclusión educativa como vía para incorporar de forma completa a todo el alumnado al sistema educativo, es decir desde el acceso, la permanencia y procurando la promoción del alumnado para completar su función como ciudadano activo y parte de la sociedad pues nadie puede excluirse del pacto social en un Estado social y democrático de Derecho, como indica Muñoz Villalobos (2008) "La educación refleja y subvierte las estructuras 
sociales y tiene la capacidad de redimensionar las prácticas de vida, los procesos de enseñanza y de aprendizaje y, ciertamente la constitución de la ciudadanía" (p.109). En este sentido señala cinco características propias del derecho a la inclusión educativa destacando en primer lugar su naturaleza de derecho humano habilitante para el ejercicio de otros derechos. En segundo término, le adscribe un carácter instrumental al que añade también las notas de integralidad/multisectorialidad y progresividad (Muñoz Villalobos, 2019). Todas ellas favorecen el razonamiento jurídico que pueda utilizarse desde los poderes públicos, organizaciones y movimientos sociales para superar las barreras que limitan este derecho a una educación inclusiva plena mediante la argumentación y el diálogo de los derechos. Esta pretensión busca la plena igualdad de todos los ciudadanos en el sistema educativo y en la sociedad coincidiendo con la meta 4.5 de los Objetivos del Desarrollo sostenible cuando se refiere a que se pretende de aquí a 2030 asegurar el acceso igualitario a todos los niveles de la enseñanza y la formación profesional para las personas vulnerables, incluidas las personas con discapacidad, los pueblos indígenas y los niños en situaciones de vulnerabilidad. España se ha comprometido con el impulso de los medios para hacer tales objetivos posibles, entre ellos el derecho es uno de los más eficaces para incorporar en las políticas y en las normas el reconocimiento y por tanto la exigencia y garantía del derecho real y efectivo de inclusión en el acceso, la permanencia y de promoción dentro del sistema educativo.

Se impone la educación inclusiva como derecho humano consagrado en el art. 24 de la Convención Internacional de Derechos de las Personas con Discapacidad (CIDPD en adelante) que recoge el ordenamiento jurídico español tal y como queda reflejado en el art. 1 de la LOE (Ley Orgánica de Educación) y la normativa autonómica que la desarrolla. La regulación internacional propone claramente este derecho de tercera generación que exige la participación del Estado. Sin embargo, en España su regulación se enmarca constitucionalmente en el artículo 49 bajo la rúbrica de los principios rectores de la política social y económica vinculándose directamente con el derecho fundamental a la educación expresado en el artículo 27. Este nexo y su reconocimiento internacional fundamentan el contenido de un posible derecho al acceso, permanencia y promoción a la educación inclusiva. La legislación va aproximándose a tal realidad y en este sentido se manifiesta el artículo 74.3 de la ley actual ley de Educación que establece que, al finalizar el curso, atendiendo a los resultados del alumno con necesidades educativas especiales, se podrá modificar su régimen de escolarización para incluir a los estudiantes en el modelo más inclusivo.

\section{ESCOLARIZACIÓN, PERMANENCIA Y PROMOCIÓN, FRISO JURIDICO CONCEPTUAL DE LA EDUCACION INCLUSIVA}

La Ley Orgánica de Educación establece en su primer artículo que el sistema educativo español se inspira en los principios de equidad y la inclusión educativa para el desarrollo de una educación de calidad que cumple con las exigencias de la política marcada por la Unión Europea y la Agenda 20-30. En lo que a escolarización se refiere, estos principios junto con el de normalización representan la incorporación al sistema educativo del alumnado no sólo con necesidades educativas especiales sino todos aquellos susceptibles de ser discriminados por razones como indica el artículo 14 de la Constitución de nacimiento, raza, sexo, religión, opinión o cualquier otra condición o circunstancia personal o social. Aunque la denominada ley Celaa parece que pudiera abrir el camino al derecho al que nos venimos refiriendo con algunas modificaciones plausibles, es con la lectura profunda del Título II cuando podemos determinar que la Ley da continuidad al modelo anterior, no incluyendo en su articulado el derecho a la inclusión en términos de acceso, permanencia y promoción.

En el proceso de incorporación al sistema, son las Administraciones educativas las encargadas de gestionar las medidas para identificar al alumnado y valorar de forma temprana sus necesidades, que, centrándonos en el caso del alumnado con necesidades educativas especiales, se realiza a través de un informe psicopedagógico, produciendo como consecuencia el 
correspondiente dictamen de escolarización en el que se decide la adecuada modalidad. Este informe ha sido objeto de múltiples recursos dirimidos por las familias que entendían que se vulneraba el derecho a la igualdad cuando se decidía la escolarización en un centro de educación especial y no en uno ordinario, dando lugar tales exigencias a una sustancial jurisprudencia cuyo examen ilumina la cuestión.

Echando una mirada atrás para comprender la problemática que nos ocupa, y promover racional y científicamente el contenido esencial del derecho de acceso, permanencia y promoción a la educación inclusiva, podemos hablar a mediados de los años 80 del pasado siglo de una primera etapa en la evolución jurisprudencial, que se concretaría en las primeras Sentencias del Tribunal Constitucional (TC) y del Tribunal Supremo (TS) que fueron nutriéndose por la práctica judicial hasta que el año 2014, encontramos una sentencia que aclara el derecho de escolarización de un menor que presentaba trastorno del espectro autista al que se le negó la inclusión en el sistema ordinario de educación, como magistralmente explica Rodríguez Zapatero (2018) pues a pesar de no concederse el amparo, se abrió el camino hacía el efectivo derecho a la educación inclusiva en nuestro país.

El TC español reconoce el principio general de que la educación de las personas con discapacidad debe ser inclusiva, es decir, que hay que escolarizar a estos alumnos en centros ordinarios con los apoyos y ajustes razonables necesarios. Sin embargo, establece una serie de criterios dentro de lo que denomina la necesidad de ajustes desproporcionados o no razonables a partir de los cuales justifica la escolarización de las personas con discapacidad en centros de educación especial cuando las necesidades específicas del menor no puedan ser atendidas en el marco de las medidas de atención a la diversidad de los centros ordinarios (Bastida, F.J., Villaverde, I., Requejo, P., Presno, M.A., Aláez, B. y Sarasola, I.F., 2004).

En este sentido se manifiesta también la jurisprudencia del TS sobre lo que considera el contenido esencial del derecho a la educación inclusiva, es decir, el derecho al acceso en el sistema educativo ordinario en igualdad sin ningún tipo de discriminación. En concreto, en la Sentencia 1976/2017, el TS desestimó el recurso de casación interpuesto por la Comunidad Autónoma de la Rioja, fundamentando la vinculación del derecho a la igualdad y el derecho a la educación, artículos 14 y 27 de la Constitución, pues su interpretación conjunta concreta el contenido esencial del derecho fundamental a la igualdad en el acceso a la educación. Interesa destacar su fundamento de derecho tercero, donde se expresa que las normas han de interpretarse conforme a los Tratados Internacionales refiriéndose al artículo 24 de la CIDPD y que por ello tanto Juzgados como Tribunales, han de aplicar directamente el artículo de la Convención que considera la educación inclusiva como un derecho humano de las personas con discapacidad. Esta es la principal razón por la que la jurisprudencia mantiene que las medidas adoptadas orientadas a la inclusión deben ser necesarias y adecuadas con el único límite que no supongan una carga desproporcionada. Este reconocimiento a la educación inclusiva como un derecho cuyo ejercicio depende de elementos externos a su titular, nos lleva a hablar aquí de un derecho condicionado, lo que desvirtúa su naturaleza de derecho, como indica magistralmente Dworking hablando de los derechos en serio.

Los derechos individuales son triunfos políticos en manos de los individuos. Los individuos tienen derechos cuando, por alguna razón, una meta colectiva no es justificación suficiente para negarles lo que, en cuanto individuos, desean tener o hacer, o cuando no justifica suficientemente que se les imponga alguna pérdida o perjuicio (1993, p .37).

En cuanto a la permanencia en el sistema educativo, completa el acceso en régimen de inclusión, garantizándose la igualdad y la no discriminación de los alumnos con otras capacidades. Para ello la Administración educativa cuenta con medios que procuren apoyos y atenciones educativas, específicas, personalizadas y efectivas para los alumnos con necesidades educativas especiales lo que posibilita la integración. Tales acciones han de estar orientadas en función de las 
características personales y las necesidades concretas que tenga cada alumno. Para ello se realizan, en el caso de la discapacidad evaluaciones psicopedagógicas, que salvo casos excepcionales, hoy en día se centran en los déficits del alumnado poniendo de manifiesto las barreras que presentan ante las distintas áreas del desarrollo.

Este modelo clínico-sanitario incompatible con la concepción actual de la discapacidad desde la perspectiva social y propia de los derechos fundamentales, prioriza factores de diferenciación y de exclusión de los alumnos como indica el Comité de Naciones Unidas sobre la Convención, en el Comentario General N. "4/2016, cuando señala que "la educación de las personas con discapacidad a menudo se centra en un enfoque del déficit, en su deficiencia real o aparente, limitando sus oportunidades debido a asunciones predefinidas negativas sobre su potencial", lo mismo ocurre al respecto de los demás alumnos que por diferentes razones pueden ser discriminados.

Para paliar esta adversidad el concepto de diseño universal para el aprendizaje, resulta junto con otras herramientas derivadas de la innovación docente útiles en el campo de la atención a la diversidad y de la pedagogía inclusiva. Aceptar que todos los alumnos pueden aprender juntos y que su participación en el proceso de aprendizaje requiere respuestas propias a las diferencias individuales sin que importen ni las habilidades, ni capacidades ni competencias se opone a la pedagogía especializada para alumnos con capacidades diferentes (Florian \& Kershner, 2009, Florian, 2010, Florian \& Black-Hawkins, 2011).

Facilitarían el ejercicio del derecho a la permanencia con modelos de enseñanza abiertos que eliminan limitaciones y barreras para aprender a aprender, considerando a todos los estudiantes sin diferencia alguna entre ellos con el menor número de ajustes individuales posibles, promoviendo las habilidades a través de estrategias dirigidas al aprendizaje de todos por igual. Cubren "la necesidad de disponer de marcos conceptuales y de aplicación de enfoques sobre accesibilidad y diseño para todos" (Ruiz Bel, Solé Salas, Echeita Sarrionandia, Sala Bars y Datsira Gallifa, 2012, p.416).

En cuanto a la promoción como tercer elemento del friso que configura la visión integral del derecho a la educación inclusiva, la ley actual valora las adaptaciones curriculares significativas del alumnado con alteraciones graves y permanentes a favor de la promoción y la titulación en equidad lo que según ya indicaba Peces-Barba (1986) hace más de 30 años, favorece la competitividad, compatible con una sociedad desigual que sólo favorece la igualdad del punto de partida. En cuanto al punto de llegada, se refiere a la igualdad material representada por determinados niveles de igualdad en la meta, entendiendo que "ese objetivo sólo se puede alcanzar con la tesis de la igual satisfacción de las necesidades básicas” (p.169), a las que está compelido el Estado social.

No cumplir con este objetivo de permanencia y promoción, puede llevar a la discriminación, ante la que los poderes públicos y el derecho han articulado un plexo normativo e institucional al servicio de la igualdad y la libertad que se concreta en los mecanismos de garantía, protección y exigencia de los derechos fundamentales del que no queda exceptuado el sistema educativo que ha de contemplar la educación permanente como el ejercicio del derecho a la educación en cualquier etapa de aprendizaje de la vida de una persona.

A través del posible del acceso, permanencia y promoción se concreta el empoderamiento de los destinatarios de las políticas educativas de inclusión, reconociéndose que son titulares de derechos que generan obligaciones al Estado siendo este abordaje el de los procesos sociales de las últimas décadas (Pautassi, 2010). Este es el proceso básico que ha impulsado el reconocimiento de los derechos frente al poder como esferas de protección de la dignidad del individuo en todas sus manifestaciones, donde las reglas sólo pueden ser cumplidas o no, mientras que los principios ordenan que algo sea cumplido en la mayor medida posible (Alexy, 1993, p. 144). 


\section{LA NATURALEZA JURÍdica DE LA INCLUSIÓN EDUCATIVA, PRINCIPIO Y DERECHO}

Efectivamente los principios como expresión concreta de valores impulsan el reconocimiento de derechos que son expresados normativa e institucionalmente, en concreto en ámbito internacional la CIDPD es la norma de referencia sobre la plena inclusión en la sociedad, y particularmente de la educación inclusiva, estableciendo de forma explícita que los países signatarios de la Convención de la ONU han de asegurar un sistema de educación inclusivo a todos los niveles, así como la enseñanza a lo largo de la vida. Es decir, se comprometen a la adecuación normativa y el desarrollo de políticas activas en el mundo de la discapacidad que han de ir dirigidas a contemplar dichos aspectos. Los efectos constitucionales de la participación de España en la Conferencia se resumen en que de conformidad con el artículo $96 \mathrm{CE}$, su contenido es directamente aplicable y además por su vinculación con la dignidad y los derechos humanos cumpliendo con el artículo 10.2 CE han de servir de criterio interpretativo y orientativo tanto de la gestión del Estado y sus instituciones, como a la política y a la administración de justicia.

Así lo han entendido en el ámbito de la Unión Europea que desde comienzos de siglo viene desarrollando políticas a favor de la inclusión educativa y social, lo que ha tenido un reflejo normativo que ha supuesto una tendencia generalizada a disminuir progresivamente la escolarización en Centros para alumnos con necesidades educativas diferentes. En los últimos años, curiosamente nos encontramos con una ligera corrección de esta tendencia a lo que contribuye, de un lado, la clara irreversibilidad de estas instituciones, que casi nunca derivan alumnos hacia los centros ordinarios, y la creciente presencia de alumnos con problemas graves de conducta que no quieren ser atendidos por instituciones ordinarias, principalmente en el nivel de enseñanza secundaria.

Como indica López-Torrijo (2009) fueron los años 90 los primeros en recoger las leyes básicas que regularon la inclusión, así Portugal en 1991, Islandia en 1992, Chipre y Noruega en 1999 y Grecia en el 2000. Se manifiestan como la vanguardia legislativa de la inclusión, recogiendo los dictados de las Declaraciones Internacionales en su ordenamiento jurídico, a través de una educación igualitaria y el derecho a la inclusión. Desde la prevención y detección de la discapacidad, hasta los planes de autonomía personal y transición a la vida adulta se recogen así las tres dimensiones de la educación inclusiva, acceso, permanencia y promoción. En este sentido destaca la experiencia italiana, que aplicando el Informe Warnock de 1978 marcó en las últimas décadas del siglo XX la esencia de un sistema educativo integrador incluyendo a los alumnos con discapacidad en las clases comunes en toda modalidad y nivel formativo, tal y como expresa su Constitución. Igualmente destacable es el modelo islandés que promueve la normalización regulando aspectos generales de los estudiantes con discapacidad y asegurando los recursos necesarios para atender cualquier necesidad educativa especial sin exigencias referentes a la Educación Especial en ningún nivel de su sistema educativo.

En lo que a nosotros nos interesa, en España se reconoce la igualdad en el acceso a la educación como un derecho fundamental por la interpretación conjunta de los artículos 27 y 14 de la Constitución que sin embrago no cuenta con las condiciones suficientes para poder garantizarse y ejercerse por falta de medios económicos y no se hace mención a la permanencia y promoción que completan y dan coherencia al derecho de acceso. Así junto a la necesidad de desarrollo legislativo se precisa el artículo $49 \mathrm{CE}$ que se refiere a la discapacidad, para su real y efectivo disfrute resultan imprescindibles recursos que incluyan e integren realmente a las personas con discapacidad en el sistema educativo. Es en este sentido donde el principio rector de la integración de los discapacitados pone de manifiesto la necesaria actuación del Estado a través del desarrollo de políticas legislativas, educativas, económicas y sociales. Compartimos pues la visión de la discapacidad de Cuenca Gómez (2012a, 2012b) que la entiende como la 
originada no tanto por las limitaciones personales ocasionadas por el padecimiento de una deficiencia, como sostiene el modelo médico, sino por las limitaciones de una sociedad que no tiene presente en su diseño la situación de las personas con discapacidad generando barreras que las excluyen y discriminan, por lo que es la sociedad la que debe re-diseñarse para garantizar su inclusión en igualdad de condiciones (p. 89).

Desde esta perspectiva se impone la percepción de los derechos humanos como bandera que haga exigible el derecho a la inclusión educativa de forma completa. En primer lugar, implica que la cuestión de la capacidad jurídica de las personas con discapacidad se aborde desde los valores, principios y fines básicos que presiden el discurso de los derechos humanos. Siguiendo este razonamiento, la discapacidad no puede ser un obstáculo para el disfrute pleno del derecho fundamental a la educación, siendo la educación inclusiva la garantía de la igualdad de oportunidades (Medina, 2017) que se vincula directamente con el respeto, garantía y protección de la dignidad. No en vano el art. 10.1 CE, establece que la dignidad de la persona, los derechos inviolables que le son inherentes y el libre desarrollo de la personalidad son el fundamento del orden político y de la paz social, correspondiendo a los poderes públicos arbitrar la organización y los procedimientos necesarios para darles efectividad.

Los derechos fundamentales forman el núcleo de la CE, son "los componentes estructurales básicos, tanto del conjunto del orden jurídico objetivo como de cada una de las ramas que lo integran en razón de que son la expresión jurídica de un sistema de valores, que, por decisión del constituyente, ha de informar al conjunto de la organización jurídica y política" (STC 53/1985 F.J. $4^{\circ}$ ). Respecto al tema que nos ocupa, la educación inclusiva no goza de la fundamentalidad objetiva que deriva de la Constitución, ya que no se encuentra expresado como tal como hemos indicado, lo que no obsta para que se reconozca como derecho a través de la cláusula de integración del artículo 10.2 que incluye en el ordenamiento jurídico español todos los derechos expresados en las declaraciones internacionales de derechos válidamente firmadas por nuestro Estado. En la efectividad del derecho a la inclusión se ha prestado especial importancia al acceso, que ha de completarse con compromiso de los poderes públicos dirigido al fomento de la permanencia y promoción de forma que se asegure la garantía de este posible derecho (Beladiez Rojo, 2010).

Ciertamente el furor creativo de derechos de los últimos años dejó atrás exigencias y extremos de la naturaleza jurídica propia de los derechos, que quizás han contribuido a que pretensiones sin tales rasgos se confundan con los verdaderos derechos que la sociedad demanda. En nuestro caso concluimos con López Torrijo (2009) que el proceso hacia la educación inclusiva es irreversible, aunque su práctica todavía sea muy incompleta ya que las declaraciones internacionales con una notable labor ideologizadora no cuentan con la fuerza suficiente para hacer exigible los derechos que contienen.

Destacan en esta demanda los países mediterráneos que tienen un papel protagonista al encontrarse alineados en la misma pretensión. Quizás desde el plano teórico la dinamogénesis de los derechos podría justificar los derechos de la educación inclusiva que la sociedad procura como valores de solidaridad e igualdad en el siglo XXI. Junto a los derechos vinculados a la paz o al desarrollo, este derecho como expresión concreta de los denominados derechos de solidaridad no son conceptos jurídicos irreales o de contenido abstracto si no que responden diacrónica y sincrónicamente a las aspiraciones sociales de su tiempo. Si la libertad fue el valor guía de los derechos de la primera generación, los derechos de la tercera tienen como principal valor de referencia la solidaridad. En este sentido Pérez Luño (1991) mencionando a Nino recoge que:

La acción política del valor solidaridad supone una concepción de los derechos humanos como acciones positivas de los poderes públicos que justifican la adscripción de deberes positivos, es decir de obligaciones de hacer que convierten en relevante el concepto de omisión. Esta reflexión es muy importante para el 
tema que nos ocupa, ya que la omisión del reconocimiento de la educación inclusiva como un derecho humano sigue provocando situaciones de discriminación de las personas con discapacidad (p.122).

La inclusión educativa en su triple aspecto de acceso, permanencia y promoción en el sistema educativo, formaría parte de esa nueva generación de derechos humanos basados en la solidaridad de la sociedad, hablando incluso de derechos de la denominada cuarta generación que se corresponden con la manifestación amplia y real de los derechos sociales y la concreción del Estado Social y democrático de Derecho como bien explicaba el maestro Bonavides (2005).

En España la actual ley de educación promueve activamente la inclusión, si bien no la expresa como derecho, lo que aportaría un contenido concreto al principio jurídico que es la fórmula jurídica con la que se manifiesta en nuestro ordenamiento. Como tantos otros principios especialmente rectores, su desarrollo legislativo se hace imprescindible, para poder activarse como verdaderos derechos cuya exigencia y protección pueda articularse ante la jurisdicción ordinaria siguiendo la tendencia europea que considera la educación inclusiva como un derecho exigible y garantizable. Veremos más adelante esta cuestión en la que no está resuelto el grave problema de los recursos económicos como elementos imprescindibles para dotar de contenido a los derechos sociales pero que no debe frenar la argumentación para su exigencia.

\section{FUNDAMENTACIÓN AXIOLÓGICA DEL DERECHO A LA EDUCACIÓN INCLUSIVA}

Con la dinamogénesis de los valores y el derecho, Méndez Rocasolano (1999, 2014, 2018) hace referencia al proceso constante en el que los valores están inmersos y que puede resumirse en tres etapas: a) conocimiento-descubrimento de los mismos por la sociedad; b) posterior adhesión social a los mismos y c) concreción de los valores a través del derecho en su producción normativa e institucional. Se alinea con los autores que tienen la triada como referente; así Recasens (1981), y más recientemente Reale (1997), en su versión actual de la teoría tridimensional del derecho que lleva exponiendo desde finales del pasado siglo, parten de que la experiencia jurídica supone la interconexión entre hechos, normas y valores. Las normas se encuentran entre la realidad del hecho y los valores de una cultura, son las expresiones de una sociedad concreta en un momento histórico determinando, es decir, suponen un posicionamiento definido por la voluntad popular para la gestión del vivir y el devenir. La interconexión de la triada hecho, norma y valor requiere una toma de conciencia y asunción de responsabilidad que las poblaciones actuales, incorporadas al individualismo y al hedonismo del siglo de nuestros días agudizadas por el miedo que la Pandemia del Covid ha instaurado, junto con los nuevos medios de comunicación, basados en el manejo de la información desde cada uno de nosotros, nos lleve a revisar el plexo axiológico contemporáneo donde parece que todo vale (Harari 2018).

La teoría de la dinamogénesis de los valores y el Derecho se ha ensayado desde el año 2000 en varias ocasiones, utilizándola a continuación como piedra angular del proceso sobre el cual puede apoyarse la existencia del derecho fundamental a la educación inclusiva aun sin tener soporte literal en el texto constitucional, resaltando la importancia de los factores sociales, y los valores como elementos configuradores del reconocimiento del contenido esencial de posible nuevos derechos.

Un primer acercamiento al concepto descriptivo de valores nos muestra que fundamentan e inspiran el sentir social, define sus objetivos y marcan un criterio de validez. Ya he defendido anteriormente y mantengo mi opinión de que los valores residen en un espacio inaprensible por la humanidad que es capaz de percibir aquellas expresiones que el contexto histórico-cultural y social le descubren. Siendo estas expresiones la versión de los valores conectada con la percepción cultural y social, por ello mutables e históricas, que manifiestan nociones de relación y no de esencia. 
Desde la configuración triádica, los valores se encuentran en el vértice formado por las aristas de las normas y la conducta social, manifestándose el orden axiológico que da lugar al deber ser valorativo. En expresión de Derecho Político, sería el espíritu de las Constituciones, donde el Derecho se manifiesta como norma cultural y marco de pacífica convivencia. El Derecho pues ordena la conducta humana en sociedad que se adapta a esos valores, proyectándolos de acuerdo a su deber ser y rechazando aquello que se opone al deber ser de los mismos.

Siguiendo a la profesora Méndez Rocasolano el ser humano pretende conseguir lo valioso, lo que estima valioso (los valores), en soledad o en sociedad, busca incorporar a su mundo el mundo de los valores. En la conexión del hombre con el mundo axiológico, el valor que existe independientemente de la percepción del mismo toma forma y se puede percibir, los valores entonces se sienten y se demandan produciendo así su nacimiento a la realidad social y/o individual.

Podemos decir que los valores que la sociedad se autoimpone son los que valen, en ellos nos centramos siendo conscientes del interesante debate que se abre ante los que se rechazan o se ignoran, cuyo desarrollo excede de estas líneas y dejamos dibujado al albur del lector. El conjunto de los valiosos forma el sentimiento axiológico de la sociedad que ha de estar en coherencia con los denominados valores superiores del ordenamiento jurídico, la libertad, la justicia, la igualdad y el pluralismo político además de la dignidad de la persona y los derechos que les son inherentes.

La única norma que es capaz de expresar tal realidad es la Constitución cuyo vértice se define por la línea del sentimiento axiológico y la sociedad, representado de esta forma el sentir de una sociedad de forma clara y precisa, al articular los valores que la ciudadanía estima como los superiores del ordenamiento jurídico configurándose el marco de convivencia en un Estado.

Así pues, si el Derecho regula la convivencia humana en sociedad a través de normas que reflejan el sentimiento axiológico de la sociedad, ocurre que en las actuales son sociedades globalizadas, líquidas y abiertas, que el Derecho se desarrolla a través de fuerzas que no se tienen tan localizadas como antaño (Bauman 2020). El Derecho hoy ha de mantenerse sólidamente como un marco referencial de la convivencia pacífica en sociedad para garantizar y amparar lo valioso que pasa del plano ideal al real, a través de las normas que protegen, exigen o garantizan su contenido. Este es el caso de la inclusión educativa que ha de inspirar la acción vehicular de las normas y también de las instituciones que debe concretar las expresiones axiológicas de igualdad, libertad y dignidad de la persona que incluye. En concreto, los valores vinculados a la igualdad de oportunidades por parte del sistema educativo para todos. Aquí, es posible encontrarnos con valores que son sentidos por la sociedad pero que todavía el Derecho no ha regulado. La cuestión reside en que superar los obstáculos que impiden dan consistencia jurídica a los valores inscritos en el sentimiento axiológico de la sociedad, obstáculos que superados han dado lugar a las grandes declaraciones de los derechos del hombre y a los cambios de paradigmas que todos conocemos expresados en las grandes declaraciones de Derechos de la Humanidad.

Ya son múltiples las voces que, desde el ámbito de las Declaraciones, las familias de los afectados y la literatura especializada reclaman el reconocimiento y garantía de los derechos de acceso, permanencia y promoción de los discapacitados en el sistema educativo ordinario. Si el sentimiento axiológico de la sociedad no tiene dentro del Derecho su reflejo, podemos decir que ese Derecho no satisface los intereses que la sociedad demanda, no cumple con su función.

La exigencia normativa supone su utilidad y necesidad social, la ciudadanía "siente" su carácter instrumental al servicio de la comunidad. Cuando pierden este carácter con independencia de su derogación, dejan de valer y su deber ser se desvanece en el sentimiento social. Los valores son cuando valen, es decir, tienen contenido cuando son reflejo de un valor que la sociedad o el individuo le otorgan, despliegan entonces todos sus efectos incluyéndose en la expresión de hacer o no hacer que la norma representa. En el Estado Social y Democrático de Derecho español las normas son expresión de la soberana voluntad popular y así la defensa de los dictados de la mayoría se pone al servicio de la sociedad, del ordenamiento jurídico y sus instrumentos para imponer y exigir su cumplimiento a través de medidas preventivas y represivas. 
Vengo explicando desde hace dos décadas que la juridificación valorativa constituye una realidad que descubre valores que antes se hallaban tras el velo del desconocimiento, ahora podría decir desde la experiencia, también detrás de la veladura del interés o los intereses vinculados al poder, y lo hace a través de un proceso que puede aplicarse a la educación inclusiva en España incluyendo junto a la naturaleza jurídica de principio rector la de derecho. En el comienzo del proceso que representa la dinamogénesis de los valores, que podríamos llamar momento inicial, el valor existe en el que llamamos mundo de los valores. A continuación, el desarrollo social, político, económico y técnico posibilita su conocimiento. Podemos decir que la humanidad descubre el valor, la sociedad lo siente como valioso, lo demanda y protege. Tal es el caso del acceso, permanencia y promoción de la educación inclusiva, manifestaciones concretas de la dignidad de la persona y de los derechos que le son inherentes, no en vano fundamento el orden jurídico y la paz social según el artículo 10.2 de nuestra Constitución como hemos apuntado arriba.

Ciertamente los valores en torno a la educación inclusiva se han incorporado a las normas e instituciones actuales dibujando un concreto derecho fundamental de los niños en general y los que presentan discapacidades y son posibles sujetos de discriminación en particular. Se concreta así la acción dirigida a los poderes públicos y su función interpretadora a través de un compromiso con la infancia mediante el mandato directo y finalista que se impone a los poderes públicos para convertir los valores de la inclusión en acciones, es decir, en realidades concretas para las personas con discapacidad como bien apunta Booth (2006).

Como en numerosas ocasiones ha indicado la doctrina y la jurisprudencia el ordenamiento jurídico es dinámico en cuanto que ordena relaciones de convivencia humana y ha de responder a la realidad social de cada momento, como instrumento de progreso y perfeccionamiento. Con la concreción del derecho de acceso, permanencia y promoción de la educación inclusiva tiene una magnífica oportunidad para demostrarlo.

Tabla 1

Resultado de la dinamogénesis de los valores aplicada a la educación inclusiva

\begin{tabular}{|c|c|}
\hline Mundo abstracto de los valores & $\begin{array}{l}\text { El valor de la educación inclusiva es una entidad } \\
\text { abstracta }\end{array}$ \\
\hline $\begin{array}{l}\text { Sentimiento axiológico de la sociedad que a partir } \\
\text { del año } 2000 \text { se adhiere a los valores que } \\
\text { representan la educación inclusiva }\end{array}$ & $\begin{array}{l}\text { El valor de la educación inclusiva se siente } \\
\text { valioso, el valor es en la realidad social. Surge el } \\
\text { interés y la problemática circunscrita a la } \\
\text { educación inclusiva. }\end{array}$ \\
\hline $\begin{array}{l}\text { Juridificación del valor (inclusión en el } \\
\text { ordenamiento jurídico a través de la LOE) }\end{array}$ & $\begin{array}{l}\text { El valor se garantiza y protege a través del } \\
\text { Derecho. La Constitución Española lo protege y } \\
\text { lo expresa en el art. } 49\end{array}$ \\
\hline $\begin{array}{l}\text { Juridificación del valor (inclusión en el } \\
\text { ordenamiento jurídico) }\end{array}$ & $\begin{array}{l}\text { El valor se protege y garantiza a través del } \\
\text { Derecho. La Constitución Española lo recoge en } \\
\text { el art. } 49 \text { como una norma vinculante, pero de } \\
\text { dudosa eficacia. Es un deber ser declarativo }\end{array}$ \\
\hline $\begin{array}{l}\text { Desarrollo del mandato constitucional a través de } \\
\text { una Ley de Desarrollo que reconozca la } \\
\text { existencia de un derecho. }\end{array}$ & El valor se convierte en un deber ser eficaz \\
\hline
\end{tabular}




\section{REFERENCIAS BIBLIOGRÁFICAS}

Ainscow, M., Farrell, P. \& Tweddle, D. (2000). Developing policies for inclusive education: A study of the role of local education authorities. International Journal of Inclusive Education, 4(3), 211-229.

Alexy, R. (1993). Teoría de los derechos fundamentales. Centro de estudios Ramón Areces.

Bastida, F.J., Villaverde, I., Requejo, P., Presno, M.A., Aláez, B. y Sarasola, I.F. (2004). Teoría general de los derechos fundamentales en la Constitución Española de 1978. Tecnos.

Bauman, Z. (2020). Sobre la educación en un mundo líquido. Paidós Ibérica.

Beladiez Rojo, M. (2010). Los principios jurídicos. Civitas.

Blanco, R. (2006). La equidad y la inclusión social: uno de los desafíos de la educación y la escuela hoy. Revista Electrónica Iberoamericana sobre Calidad, Eficacia y Cambio en Educación, 4(3), 1-15.

Blanco, R. (2010). El derecho de todos a una educación de calidad. Revista Latinoamericana de Educación Inclusiva, 4(2), 25-153.

Bonavides, P. (2005). Curso de direito constitucional. Malheiros.

Booth, T. (2006). Manteniendo el futuro con vida; convirtiendo los valores de la inclusión en acciones”. En Verdugo, M.A. y Jordán de Urríes, F.B. (Coords.), Rompiendo inercias. Claves para avanzar. VI Jornadas Científicas de Investigación sobre Personas con Discapacidad. (pp. 211-217). Amarú.

Connolley, S. \& Sarromaa Hausstäter, R. (2009). Tocqueville on democracy and inclusive education: a more ardent and enduring love for equality than for liberty. European Journal Of Special Needs Education, 24(3), 231-243.

Cuenca Gómez, P. (2012a). El sistema de apoyo en la toma de decisiones desde la Convención Internacional sobre los Derechos de las Personas con Discapacidad: principios generales, aspectos centrales e implementación en la legislación española. REDUR 10, 61-92.

Cuenca Gómez, P. (2012b). La incidencia del derecho internacional de los derechos humanos en el derecho interno: la interpretación del artículo 10.2 de la Constitución Española. Revista de Estudios Jurídicos $n^{\circ} 12$.

Dworking, R. (1984). Los derechos en serio. Ariel.

Dyson, A. (2001). Dilemas, contradicciones y variedades de la inclusión. En Verdugo, M.A. y Jordán de Urríes, F.B. (Coords.), Apoyos, autodeterminación y calidad de vida (pp. 145-160). Amarú. 
Echeita, G. y Ainscow. M. (2011). La educación inclusiva como derecho. Marco de referencia y pautas de acción para el desarrollo de una revolución pendiente. Tejuelo. Didáctica de la Lengua y la Literatura. Vol. 12. 67-98.

Echeita, G. (2008). Inclusión y exclusión educativa. Voz y quebranto. REICE - Revista Electrónica Iberoamericana sobre Calidad, Eficacia y Cambio en Educación 2008, 6 (2), 9- 18.

Echeita, G. (2010). Alejandra L. S. o el dilema de la inclusión educativa en España. En Arnaiz, P., Hurtado, Ma.D. y Soto, F.J., 25 años de Integración Escolar en España. Tecnologías e inclusión en el ámbito educativo, laboral y comunitario. (pp. 1- 13). Consejería de Educación, Formación y Empleo de Murcia.

Escudero, J.M. y Martínez, B. (2011). Educación inclusiva y cambio escolar. Revista Iberoamericana de Educación, 55, 85-105.

Florian, L. (2010). The concept of inclusive pedagogy. En Hallett, G. y Hallett, F. (eds.). Transforming the role of the SENCO. Open University Press Buckingham, 61-72.

Florian, L. \& Black-Hawkins, K. (2011). Exploring Inclusive Pedagogy. British Educational Research Journal, 37 (5), 813-828.

Florian, L., \& Kershner, R. (2009). Inclusive Pedagogy. En Daniels, H., Lauder, H. \& Porter, J. (Eds.) Knowledge, Values and Educational Policy: A Critical Perspective in education (Vol. 2, pp. 173-182). Routledge.

Harari, Y.N. (2018). 21 lecciones para el siglo XXI. Penguin Random House Grupo Editorial España.

López-Torrijo, M. (2009). La inclusión educativa de los alumnos con discapacidades graves y permanentes en la Unión Europea. RELIEVE, 15 (1), 1-20.

Medina García, M. (2017). La educación inclusiva como mecanismo de garantía de la igualdad de oportunidades y no discriminación de las personas con discapacidad. Una propuesta de estrategias pedagógicas inclusivas. Colección Convención ONU, 21 (2), 52-67.

Méndez Rocasolano, M. (2014). La Teoría de la dinamogénesis de los valores y el Derecho a un Estado Social. En Bonavides, P. Del Estado liberal al Estado Social. Astrea.

Méndez Rocasolano, M. y Marín González, L.A. (2018). Perfiles axiológicos sobre la naturaleza normativa a propósito de la eficacia y la eficiencia en materias fundamentales para la supervivencia. El caso de las normas voluntarias de gestión ambiental. Revista de Direito Brasileira,19 (8), Jan. /Abr. $70-83$.

Muñoz Villalobos, V. (2008). Un mar en la niebla: apuntes para una nueva educación. En Los derechos humanos en las sociedades contemporáneas. Colección Diálogos / Fórum Universal de las Culturas Monterrey 200 Fondo Editorial de NL 109. 
Muñoz Villalobos, V. (2019). https://redclade.org/noticias/vernor-munoz-un-estado-que-eliminala-perspectiva-de-genero-en-la-educacion-ni-de-lejos-puede-considerarse-un-estado-inclusivo

Pautassi, L. (2010). Perspectivas de derechos, políticas públicas e inclusión social. Debates actuales en la Argentina. Biblos.

Peces-Barba, G. (1986). Los valores superiores. Tecnos.

Pérez Luño, A.E. (1991). Las generaciones de Derechos Humanos. En revista del CEC, $n^{\circ} 10$, septiembre- diciembre, 203-217.

Reale, M. (1997). Teoría tridimensional del derecho: una visión integral del derecho. Tecnos.

Recasens Siches, L. (1981). Introducción al estudio del Derecho, 6ª edición. Porrua

Rodríguez Zapatero, J. (2018). La doctrina jurisprudencial sobre el derecho a la educación inclusiva: evolución. La sentencia del tribunal supremo de 14 de diciembre de 2017 en Anales de derecho y discapacidad nº 3, junio 2018, Año III, 107-125.

UNESCO (2003). Superar la exclusión mediante planteamientos integradores de la educación. UNESCO.

UNESCO (2005). Guidelines for inclusión: Ensuring Access to Education for All. UNESCO.

United Nations (2005). Violence against Disabled Children. United Nations. 